\title{
Interstitially carbon-alloyed refractory high-entropy alloys with a body-centered cubic structure
}

\author{
Yanwei Cui ${ }^{1,2,3}$, Qinqing Zhu ${ }^{1,2,4}$, Guorui Xiao ${ }^{1,2,3}$, Wuzhang Yang ${ }^{1,2,4}$, Yabin $\mathrm{Liu}^{3}$, Guang-Han Cao ${ }^{3}$ and \\ Zhi $\operatorname{Ren}^{1,2^{*}}$
}

\begin{abstract}
The introduction of carbon interstitials into high-entropy alloys (HEAs) provides an effective way to improve their properties. However, all such HEA systems explored so far are limited to those with the face-centered-cubic $(\mathrm{fcc})$ structure. Here we report the structural, mechanical and physical properties of the refractory $\left(\mathrm{Nb}_{0.375} \mathrm{Ta}_{0.25} \mathrm{Mo}_{0.125^{-}}\right.$ $\left.\mathrm{W}_{0125} \mathrm{Re}_{0.125}\right)_{100-x} \mathrm{C}_{x}$ HEAs over a wide $x$ range of $0 \leq x \leq 20$. It is found that, whereas the starting HEA $(x=0)$ is composed of a major body-centered-cubic (bcc) phase with significant impurities, the bcc phase fraction increases with the $\mathrm{C}$ concentration and achieves almost $100 \%$ at $x=20$. Moreover, the increase of $\mathrm{C}$ content $x$ results in an expansion of the bcc lattice, an enhancement of the microhardness, an increase in residual resistivity and a small variation of density of states at the Fermi level. All these features are consistent with the expectation that carbon atoms occupy the interstitial site. For $x$ $\geq 11.1$, the $\mathrm{X}$-ray photoelectron spectroscopy indicates the bond formation between the carbon and metal atoms, suggesting that some carbon atoms may also reside in the lattice site. In addition, a semiquantitative analysis shows that the enhanced mixing entropy caused by carbon addition plays a key role in stabilizing the (nearly) single solid-solution phase. Our study not only provides the first series of carbon interstitial HEAs with a bcc structure, but also helps to better understand the alloying behavior of carbon in refractory HEAs.
\end{abstract}

Keywords: body-centered cubic structure, carbon-alloyed, highentropy alloys

\section{INTRODUCTION}

Recently, the concept of high-entropy alloys (HEAs) has received widespread attention as a new strategy for the alloy design [1-5]. In principle, HEAs contain at least five metallic elements with near equimolar concentrations, which leads to a high mixing entropy. This significantly reduces the Gibbs free energy and stabilizes single solid-solution-like phases with simple crystal structures, such as body-centered-cubic (bcc), face-centered-cubic (fcc) and hexagonal closed packing (hcp). Compared with traditional alloys based on one or two elements, HEAs have severe lattice distortion and can exhibit better ductility [6] and higher strength [7-12], improved corrosion resis- tance [13-18], and enhanced thermal stability [19-21]. Of particular interest are the HEAs made up of the refractory elements with high melting points. Representative examples include $\mathrm{Nb}_{25} \mathrm{Ta}_{25} \mathrm{Mo}_{25} \mathrm{~W}_{25}$ [22,23], $\mathrm{V}_{20} \mathrm{Nb}_{20} \mathrm{Ta}_{20} \mathrm{Mo}_{20} \mathrm{~W}_{20}$ [22,23], $\mathrm{Re}_{x} \mathrm{Nb}_{25} \mathrm{Ta}_{25} \mathrm{Mo}_{25} \mathrm{~W}_{25}$ [24], and $\mathrm{Nb}_{20} \mathrm{Ta}_{30} \mathrm{Mo}_{15} \mathrm{~W}_{20} \mathrm{Re}_{15}$ [25], all of which have a bcc structure. These refractory HEAs exhibit exceptional hardness greater than any individual constituent element and strong resistance to high-temperature softening $[22,23]$. Especially, their high-temperature mechanical properties are comparable to or better than those of Ni-based superalloys, which makes them promising in aerospace applications such as thermal protection systems and gas turbine engines.

The presence of interstitial carbon atoms is known to improve the mechanical and physical properties of HEAs. However, nearly all studies focus on the HEAs with a fcc structure [26-30] and the highest carbon concentration is limited below 8.9 at\% [30]. On the contrary, the alloying of carbon with bcc-structured HEAs has been rarely investigated. According to Zhang et al. [31], the structure and lattice constant of the $\mathrm{Nb}_{20} \mathrm{Ta}_{30} \mathrm{Mo}_{15^{-}}$ $\mathrm{W}_{20} \mathrm{Re}_{15}$ HEA are not affected by adding 0.1 at $\% \mathrm{C}$, although binary carbides are formed above $809^{\circ} \mathrm{C}$ at a pressure of $6 \mathrm{GPa}$. Very recently, Casilaas-Trujillo et al. [32] studied the solution energies of dilute carbon atoms in the bcc HfNbTiVZr HEA by employing theoretical calculations. The results suggest that the inclusion of carbon interstitials induces large structural relaxation with long-rang effects. Nevertheless, to our knowledge, no bcc HEA with interstitial carbon atoms has been reported to date.

It this paper, we choose the quinary refractory $\mathrm{Nb}_{37.5} \mathrm{Ta}_{25}$ $\mathrm{Mo}_{12.5} \mathrm{~W}_{12.5} \mathrm{Re}_{12.5} \mathrm{HEA}$ as a starting point. Different amounts of $\mathrm{C}$ up to $20 \mathrm{at} \%$ are added to form a series of $\left(\mathrm{Nb}_{0.375} \mathrm{Ta}_{0.25^{-}}\right.$ $\left.\mathrm{Mo}_{0.125} \mathrm{~W}_{0.125} \mathrm{Re}_{0.125}\right)_{100-x} \mathrm{C}_{x}$ HEAs, which are characterized by $\mathrm{X}$ ray diffraction (XRD), electron microscopy, $\mathrm{X}$-ray photoelectron spectroscopy (XPS), microhardness, resistivity and specific heat measurements. The results show that the system is driven toward a single bcc phase solid solution as the $\mathrm{C}$ content increases. Meanwhile, the variations of structural, mechanical and physical properties consistently suggest that carbon atoms predominantly occupy the interstitial site, though it is possible that, at high $\mathrm{C}$ contents, a small fraction of carbon atoms are located at the lattice site. In addition, the effect of $\mathrm{C}$ addition on the phase formation is also discussed.

\footnotetext{
${ }^{1}$ School of Science, Westlake University, Hangzhou 310024, China

${ }^{2}$ Institute of Natural Sciences, Westlake Institute for Advanced Study, Hangzhou 310024, China

${ }^{3}$ Department of Physics, Zhejiang University, Hangzhou 310027, China

${ }^{4}$ Department of Physics, Fudan University, Shanghai 200433, China

"Corresponding author (email: renzhi@westlake.edu.cn)
} 


\section{EXPERIMENTAL SECTION}

Ingots of $\left(\mathrm{Nb}_{0.375} \mathrm{Ta}_{0.25} \mathrm{Mo}_{0.125} \mathrm{~W}_{0.125} \mathrm{Re}_{0.125}\right)_{100-x} \mathrm{C}_{x}$ HEAs with $x=$ $0,5.9,11.1,15.8$ and 20 were prepared by melting high-purity $\mathrm{Nb}$ (99.9\%), Ta (99.9\%), Mo (99.9\%), W (99.9\%), Re (99.99\%) and C (99.5\%) elements in an arc furnace under high-purity argon atmosphere. The melts were flipped and re-melted five times to ensure homogeneity. The weight loss during the arc melting process was negligible due to the low vapor pressure of the constituent elements. Phase identification was conducted by $\mathrm{XRD}$ in the $2 \theta$ range of $20^{\circ}-120^{\circ}$ on crushed powders using a Bruker D8 Advance X-ray diffractometer with $\mathrm{Cu}$-Ka radiation. Electron backscatter diffraction (EBSD) was measured by an ultra-high resolution scanning electron microscope (SEM) equipped with a Hikari XP system in EDAX. The microstructure and chemical composition were determined on a Zeiss Supratm 55 schottky field emission SEM and a transmission electron microscope (TEM, FEI-Titan Cubed Themis G2 300) equipped with energy dispersive spectrometer (EDS). In the TEM case, the high-angle annular dark-field (HAADF) model was employed for imaging. The XPS spectra were recorded in an ESCALAB $\mathrm{Xi}+$ spectrometer with $\mathrm{Al} \mathrm{Ka} \mathrm{X-rays} \mathrm{as} \mathrm{the} \mathrm{excitation} \mathrm{source.}$ The Vickers micro-hardness $H_{\mathrm{V}}$ was measured on mechanically polished surface of the samples using an automatic microhardness testing system. The applied loads $P$ were $0.098,0.245,0.49$, $0.98,1.96,2.94,4.9,9.8$ and $19.6 \mathrm{~N}$, and $H_{\mathrm{V}}$ was calculated through [33]

$H_{\mathrm{v}}=1854.4 P / r^{2}$,

where $r$ is the mean length of the two indention diagonals. For each sample at each $P$, measurements were done on three different locations whose distance was more than three times the diagonal of the indentation, and the dwell time for each measurement was $3 \mathrm{~s}$. The electrical resistivity and specific heat measurements were performed on a Quantum Design Physical Property Measurement System (PPMS-9 Dynacool). The specific heat was measured using the thermal relaxation method. The resistivity was measured by the standard four-probe method with the gold wires attached to the sample by silver paste.

\section{RESULTS AND DISCUSSION}

\section{XRD}

The XRD patterns for the series of carbon-alloyed $\left(\mathrm{Nb}_{0.375} \mathrm{Ta}_{0.25^{-}}\right.$ $\left.\mathrm{Mo}_{0.125} \mathrm{~W}_{0.125} \mathrm{Re}_{0.125}\right)_{100-x} \mathrm{C}_{x} \mathrm{HEAs}$ are displayed in Fig. 1a. It turns out that the HEA without carbon $(x=0)$ has a multiphase nature. The major diffraction peaks can be well indexed on a bcc unit cell with the $I m-3 m$ space group, while minor diffractions due to impurity phases are detected at $2 \theta \approx 26.3^{\circ}, 35.3^{\circ}, 38.7^{\circ}$, $41.0^{\circ}$, and $59.4^{\circ}$. Remarkably, when alloying with carbon, the impurity peaks are gradually suppressed and a single bcc phase is observed for $x=20$. From Fig. 1b, one can see that the (002) peak of the HEAs tends to shift toward lower angles as the $\mathrm{C}$ content increases, indicating an expansion of the bcc lattice. This is confirmed by the $x$ dependence of lattice parameter obtained by the least-squares method shown in Fig. 1c. For $x=0$, the lattice constant $a=3.207 \AA$, which is slightly smaller than that (3.210 ̊) of the single-phase $\mathrm{Nb}_{20} \mathrm{Ta}_{30} \mathrm{Mo}_{15} \mathrm{~W}_{20} \mathrm{Re}_{15}$ HEA [25]. With increasing $\mathrm{C}$ content $x, a$ increases almost linearly up to $3.224 \AA$. Given the much smaller atomic radius of $\mathrm{C}$ in comparison with the metallic elements [34], these results strongly suggest that the $\mathrm{C}$ atoms preferentially occupy the interstitial site, which is reminiscent of that in fcc-structured HEAs [30].

\section{Microstructure and chemical characterization}

The $\left(\mathrm{Nb}_{0.375} \mathrm{Ta}_{0.25} \mathrm{Mo}_{0.125} \mathrm{~W}_{0.125} \mathrm{Re}_{0.125}\right)_{100-x} \mathrm{C}_{x}$ HEAs with $x=0$ and 20 were further characterized by the EBSD measurements. The resulting phase map and volume fraction are shown in Fig. 2a-d. It is evident that the C-free HEA consists of a mixture of the bcc and fcc phases, which are represented by the orange and blue colors, respectively. The corresponding volume factions are $76 \%$ and $24 \%$ for the two phases, which is compatible with the XRD results. In contrast, the bcc phase fraction attains $99.3 \%$
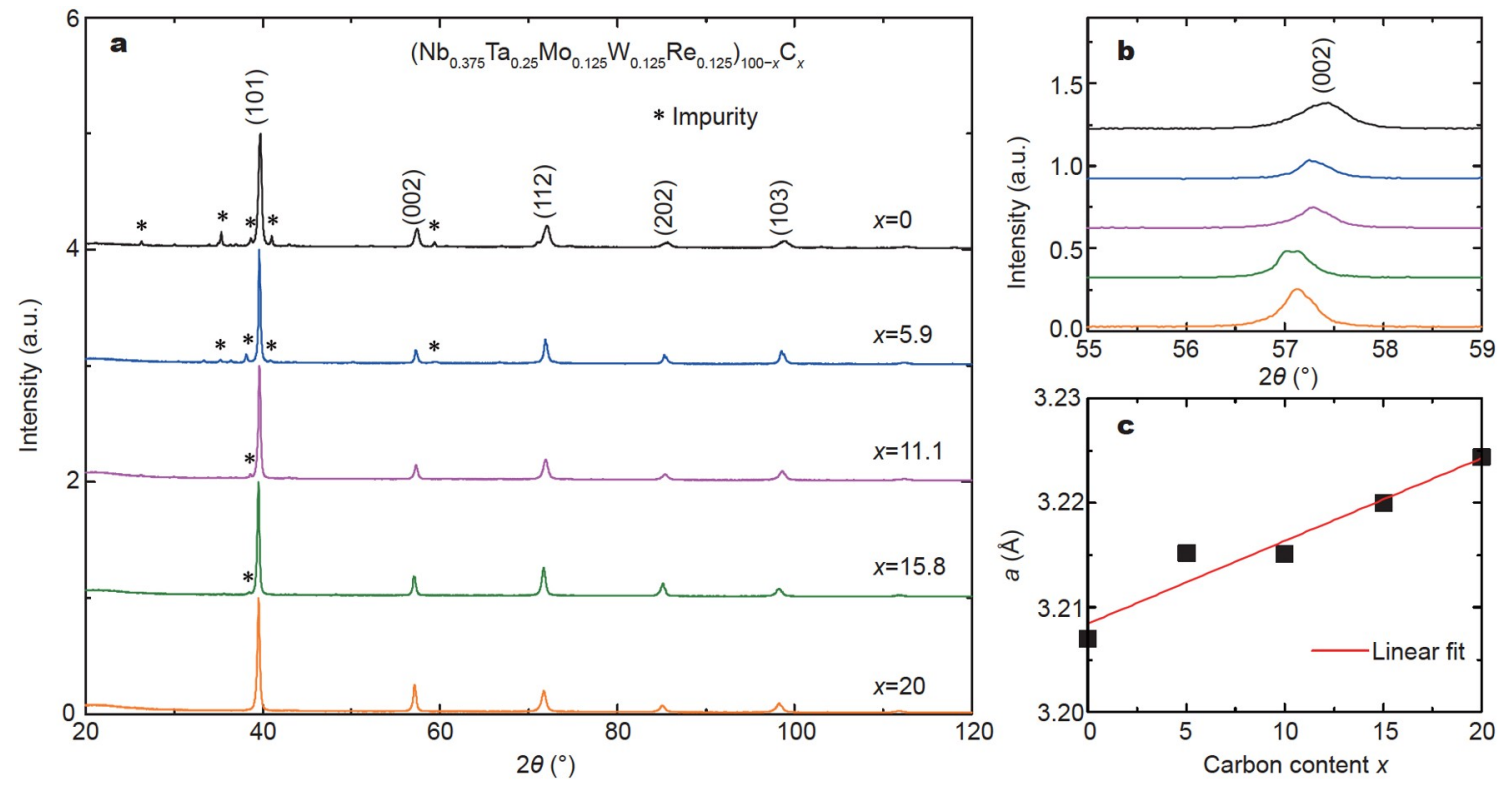

Figure 1 (a) Powder XRD patterns at room temperature for the series of $\left(\mathrm{Nb}_{0.375} \mathrm{Ta}_{0.25} \mathrm{Mo}_{0.125} \mathrm{~W}_{0.125} \mathrm{Re}_{0.125}\right)_{100-x} \mathrm{C}_{x}$ HEAs. The major diffraction peaks are indexed on a bcc unit cell and the minor ones corresponding to the impurity phases are marked by the asterisks. (b) Zoom of the (002) peaks for the HEAs. (c) Cubic lattice parameter plotted as a function of C content $x$. The solid line is a linear fit to the data with $R^{2}=0.91$. 

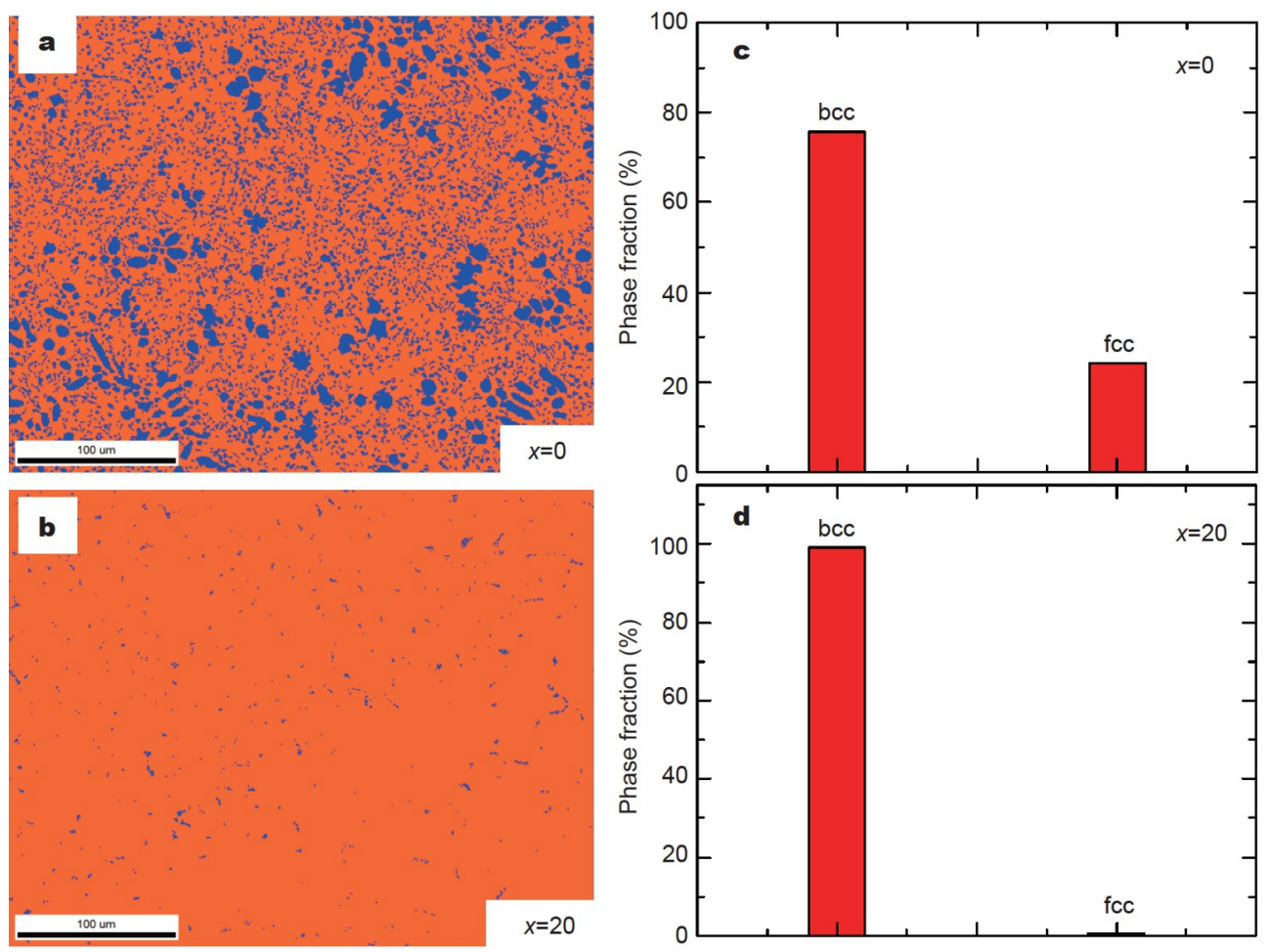

Figure 2 (a, b) EBSD phase maps for the $\left(\mathrm{Nb}_{0.375} \mathrm{Ta}_{0.25} \mathrm{Mo}_{0.125} \mathrm{~W}_{0.125} \mathrm{Re}_{0.125}\right)_{100-x} \mathrm{C}_{x}$ HEAs with $x=0$ and 20, respectively. The scale bars are $100 \mu \mathrm{m}$. $(c, d)$ Volume fractions of the bcc and fcc phases for the two HEAs, respectively.

for the HEA with $x=20$. This further substantiates the incorporation of $\mathrm{C}$ in the bcc lattice rather than the formation of carbides, which usually have an fcc or hcp structure. In addition, the average grain sizes are 28.3 and $88.4 \mu \mathrm{m}$ for the HEAs with $x$ $=0$ and 20 , respectively, signifying a grain refinement induced by carbon alloying [35].

Fig. 3a shows a typical SEM image of the $\left(\mathrm{Nb}_{0.375} \mathrm{Ta}_{0.25} \mathrm{Mo}_{0.25^{-}}\right.$ $\left.\mathrm{W}_{0.125} \mathrm{Re}_{0.125}\right)_{100-x} \mathrm{C}_{x}$ with $x=20$, or $\mathrm{Nb}_{30} \mathrm{Ta}_{20} \mathrm{Mo}_{10} \mathrm{~W}_{10} \mathrm{Re}_{10} \mathrm{C}_{20}$ HEA. On a micron scale, the HEA appears to be dense and free from voids and visible secondary phases. As displayed in Fig. $3 \mathrm{~b}-\mathrm{g}$, the energy dispersive X-ray spectroscopy (EDX) elemental mapping reveals a rather uniform distribution of $\mathrm{Nb}, \mathrm{Ta}$, Mo, W, Re and C elements. The HAADF STEM micrograph of the same HEA with a scale bar of $2 \mathrm{~nm}$ is shown in Fig. $3 \mathrm{~h}$. The absence of an ordered spatial variation of the intensity, which is proportional to the atomic number $Z^{p}$ with $p$ in the range of 1.42 , clearly indicates that all the constituent elements form a random solid solution. This is corroborated by the EDX mapping results shown in Fig $3 \mathrm{i}-\mathrm{n}$, which, together with the above results, confirm the high homogeneity of the HEA on both a macroscopic and microscopic level. In addition, the EDX measurements reveal an elemental ratio of $\mathrm{Nb}: \mathrm{Ta}: \mathrm{Mo}: \mathrm{W}: \mathrm{Re}=$ 28.5:20.6:10.2:10.9:9.8, which agrees with the nominal one within the experimental error. Here it is pointed that $\mathrm{C}$ has a very small atomic number and is a most likely contaminant in the EDX analysis, and hence its content cannot be determined accurately by the measurement.

\section{XPS spectra}

To determine the binding states of carbon in the HEAs, the XPS spectra were measured for $5.9 \leq x \leq 20$ and plotted in the $\mathrm{C} 1 \mathrm{~s}$ region in Fig. 4a. For all HEAs, there is a major peak centered at $\sim 284.8 \mathrm{eV}$ with a symmetric peak shape. This energy value is very close to the characteristic one in graphite and attributable to the interstitial carbon atoms [36]. On the higher energy side, two additional bumps are observed at $\sim 286.7$ and $\sim 288.9 \mathrm{eV}$, which correspond to carbon defects and carbon-oxygen bonds (most likely due to $\mathrm{CO}_{2}$ adsorbed on the surface) [37], respectively. In the lower energy region, a shoulder peak is discernible at $\sim 282.5 \mathrm{eV}$ for $x \geq 11.1$, and, as an example, the peak deconvolution in the energy window of $281-284 \mathrm{eV}$ for $x=20$ is displayed in Fig. $4 \mathrm{~b}$. It is worth noting that a similar binding energy of $\mathrm{C}$ is observed in binary carbides such as $\mathrm{TaC}$ [38], which points to the covalent bond formation between the metal and carbon atoms. Since there is a single crystallographic site for the simple bcc structure, this result suggests that, in addition to the interstitial site, some carbon atoms may sit in the lattice site, which is similar to that observed in C-doped $\mathrm{TiO}_{2}$ [39].

\section{Vickers hardness}

Fig. 5a shows the Vickers hardness, $H_{\mathrm{V}}$, for the series of $\left(\mathrm{Nb}_{0.375} \mathrm{Ta}_{0.25} \mathrm{Mo}_{0.125} \mathrm{~W}_{0.125} \mathrm{Re}_{0.125}\right)_{100-x} \mathrm{C}_{x}$ HEAs plotted as a function of the applied load $P$ from 0.098 to $19.6 \mathrm{~N}$. The data are averaged from three independent measurements for each $x$ value and the error bar is indicated by the vertical solid line. With increasing $P, H_{\mathrm{V}}$ of these HEAs shows an asymptotic behavior, decreasing rapidly at first and then tending to saturate. This can be understood based on the penetration depth effect of the indenter [37]. At small $P$ values, only the surface layer is affected by the indenter. Nevertheless, when the $P$ value becomes large, the inner surface plays an increasingly dominant role and finally $H_{\mathrm{V}}$ becomes independent on the applied load. The $H_{\mathrm{V}}$ at $19.6 \mathrm{~N}$ 

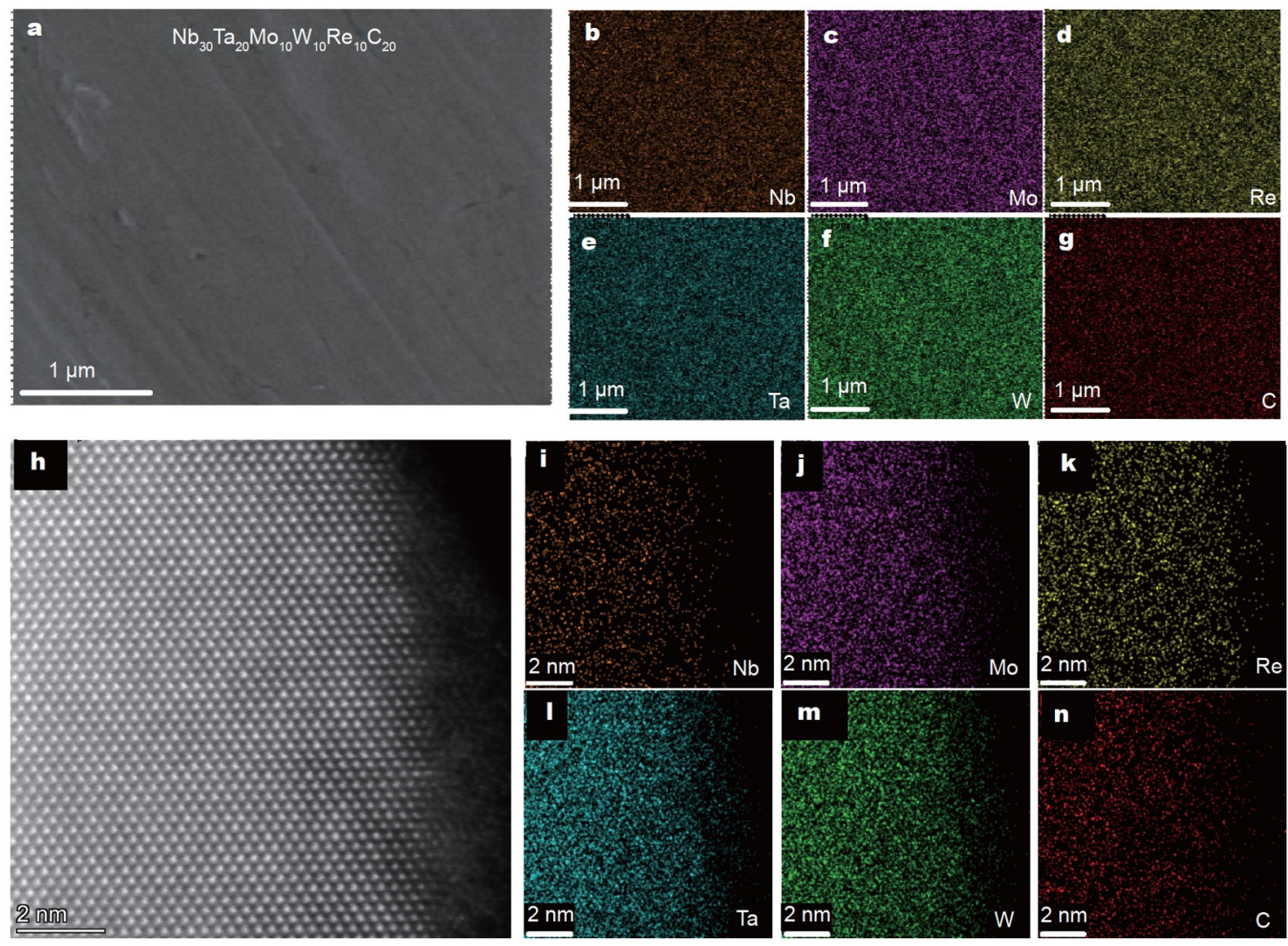

Figure 3 (a) Typical SEM image of the $\left(\mathrm{Nb}_{0.375} \mathrm{Ta}_{0.25} \mathrm{Mo}_{0.125} \mathrm{~W}_{0.125} \mathrm{Re}_{0.125}\right)_{100-x} \mathrm{C}_{x}$ HEAs $(x=20)$ HEA with the scale bar of $1 \mu \mathrm{m}$. (b-g) EDX elemental mapping for the Nb, Ta, Mo, W, Re and C elements, respectively. (h) HAADF-SEM image of this HEC with the scale bar of $2 \mathrm{~nm}$. (i-n) EDX mapping for all the constituent elements.
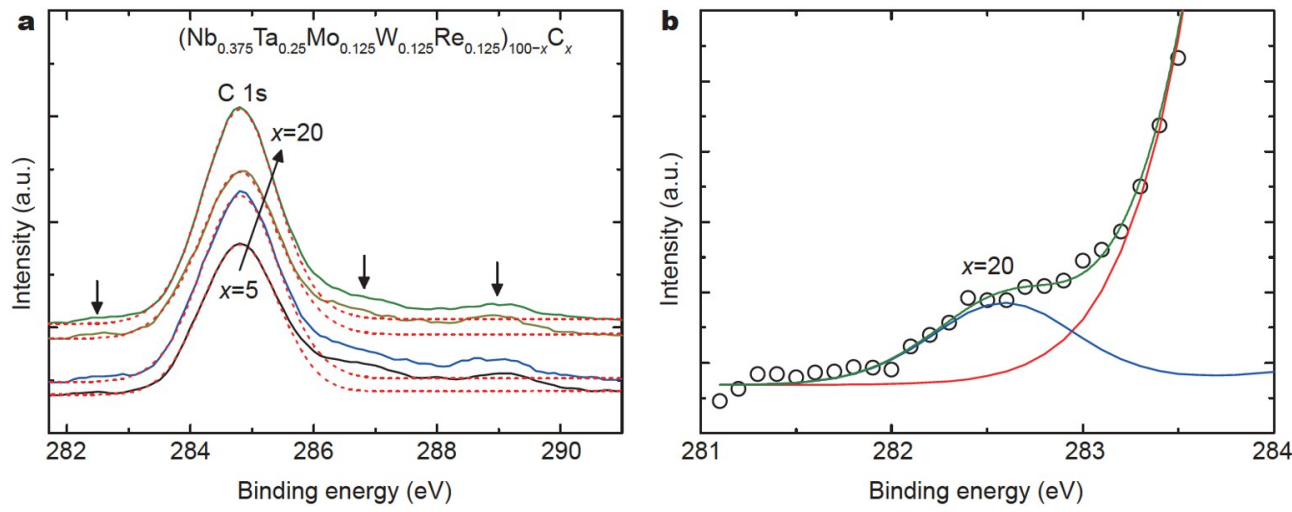

Figure 4 (a) XPS spectra in the $\mathrm{C} 1 \mathrm{~s}$ region for the $\left(\mathrm{Nb}_{0.375} \mathrm{Ta}_{0.25} \mathrm{Mo}_{0.125} \mathrm{~W}_{0.125} \mathrm{Re}_{0.125}\right)_{100-x} \mathrm{C}_{x}$ HEAs with $5 \leq x \leq 20$. The dashed lines are fit to the main peak at $\sim 284.8 \mathrm{eV}$ and the arrows mark the additional peaks for $x=20$. (b) Deconvolution of the spectrum for the HEAs with $x=20$. The existence of a small peak at $\sim 282.5 \mathrm{eV}$ is clearly visible.

is plotted as a function of $\mathrm{C}$ content $x$ in Fig. $5 \mathrm{~b}$. For $x=0$, the average $H_{\mathrm{V}}$ is $6.4 \mathrm{GPa}$, which is larger than those of bcc-type $\mathrm{Nb}_{25} \mathrm{Ta}_{25} \mathrm{Mo}_{25} \mathrm{~W}_{25}$ [22], $\mathrm{V}_{20} \mathrm{Nb}_{20} \mathrm{Mo}_{20} \mathrm{Ta}_{20} \mathrm{~W}_{20}$ [22] as well as $\mathrm{Nb}_{20} \mathrm{Ta}_{30} \mathrm{Mo}_{15} \mathrm{~W}_{20} \mathrm{Re}_{15}$ [25] HEAs. $H_{\mathrm{V}}$ exhibits a linear increase with the carbon concentration and reaches $8.0 \mathrm{GPa}$ at $x=20$, which is primarily due to interstitial solid solution strengthening. Namely, as the interstitial atoms are introduced, local stresses are formed and interact with those of the dislocations, impeding their motion and causing an increase in the hardness. In passing, the covalent metal-carbon bonds are directional and hence may also benefit the hardness response [37].

\section{Resistivity and specific heat}

The temperature dependence of resistivity $(\rho)$ for the series of $\left(\mathrm{Nb}_{0.375} \mathrm{Ta}_{0.25} \mathrm{Mo}_{0.125} \mathrm{~W}_{0.125} \mathrm{Re}_{0.125}\right)_{100-} \mathrm{C}_{x}$ HEAs is displayed in Fig. 6a. All the HEAs exhibit a metallic behavior and the $\rho(T)$ curve shifts up almost rigidly with increasing $\mathrm{C}$ content $x$. The room-temperature resistivity $\left(\rho_{300 K}\right)$ and residual resistivity ratio $\left(\rho_{300 K} / \rho_{0}\right)$ are $48.4 \mu \Omega \mathrm{cm}$ and $\sim 1.33$ for $x=0$, respectively. With increasing $x, \rho_{300 \mathrm{~K}}$ increases considerably up to $67.3 \mu \Omega$ while $\rho_{300 \mathrm{~K}} / \rho_{0}$ decreases only slightly down to $\sim 1.24$. These results clearly indicate that $\mathrm{C}$ alloying mainly leads to an enhanced disorder scattering without changing the temperature dependent 

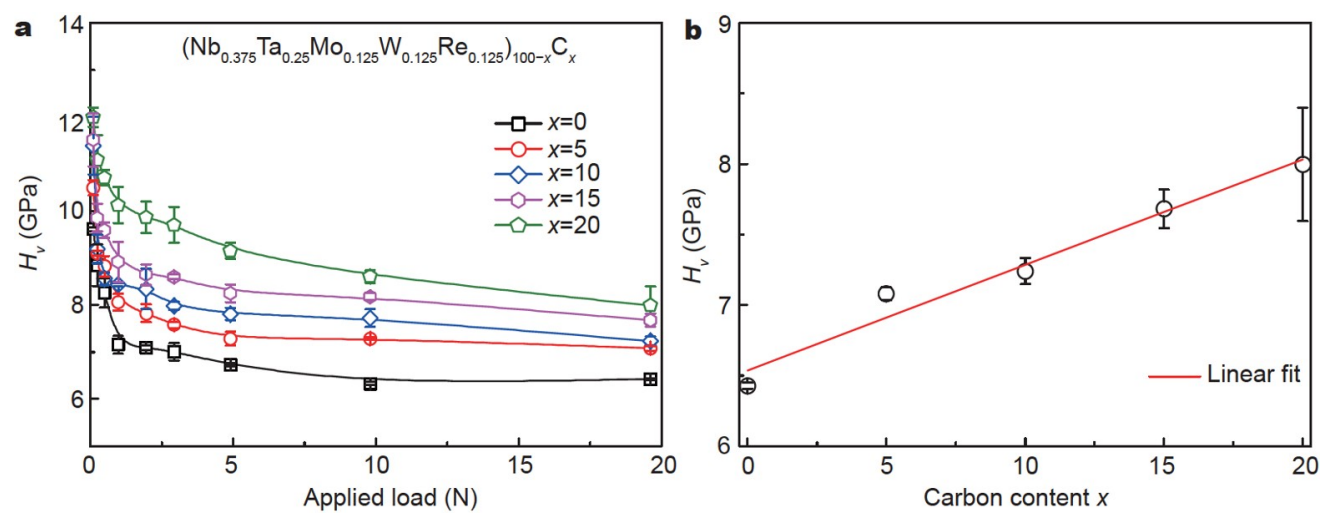

Figure 5 (a) Dependence of Vickers hardness on the applied load for the series of $\left(\mathrm{Nb}_{0.375} \mathrm{Ta}_{0.25} \mathrm{Mo}_{0.125} \mathrm{~W}_{0.125} \mathrm{Re}_{0.125}\right)_{100-x} \mathrm{C}_{x}$ HEAs . (b) Dependence of Vickers hardness at $19.6 \mathrm{~N}$ on the carbon content $x$ for the HEAs. The solid line is a linear fit to the data with $R^{2}=0.96$.
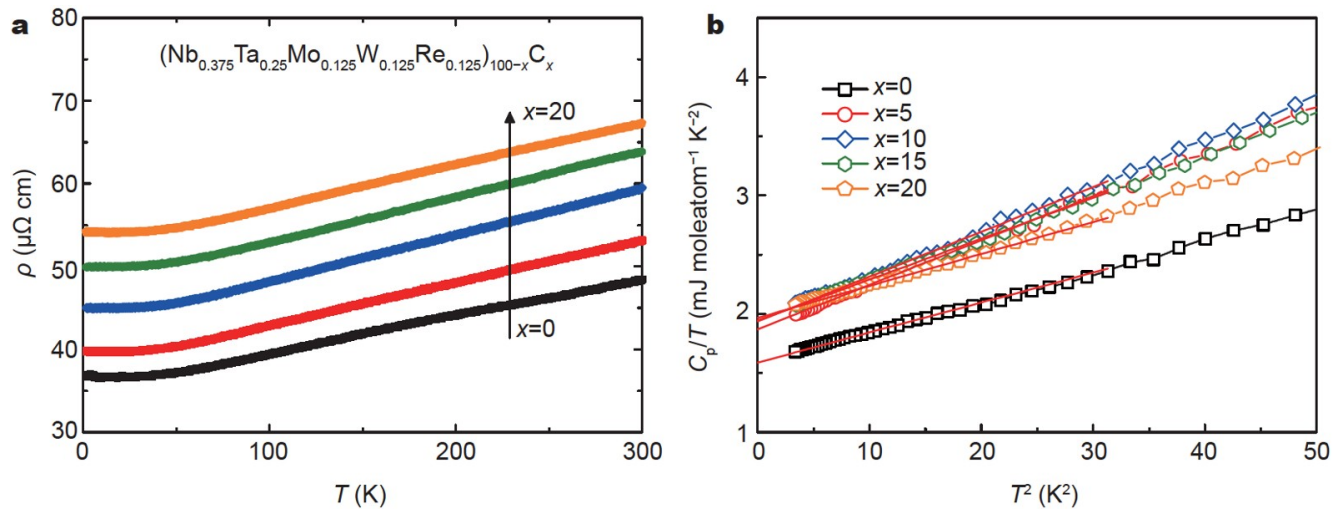

Figure 6 (a) Temperature dependence of resistivity for the series of $\left(\mathrm{Nb}_{0.375} \mathrm{Ta}_{0.25} \mathrm{Mo}_{0.125} \mathrm{~W}_{0.125} \mathrm{Re}_{0.125}\right)_{100-x} \mathrm{C}_{x}$ HEAs. The arrow marks the $\mathrm{C}$ content $x$ increasing direction. (b) Low-temperature specific heat data plotted as $C_{\mathrm{p}} / T$ versus $T^{2}$ for the series of HEAs. The solid lines are fits to the data by the Debye model.

$\rho(T)$ behavior, in line with the interstitial position of carbon atoms.

Now we turn the attention to the low-temperature specific heat $C_{\mathrm{p}}$ of these HEAs, which is plotted as $C_{\mathrm{p}} / T$ versus $T^{2}$ in Fig. $6 \mathrm{~b}$. The data are analyzed by the Debye model [40]:

$C_{\mathrm{p}} / T=\gamma+\beta T^{2}$,

where $\gamma$ and $\beta$ are the electronic and phonon specific heat coefficients, respectively. The best fits yield $\gamma=1.59,1.87,1.94$, $1.94,1.97 \mathrm{~mJ}$ moleatom ${ }^{-1} \mathrm{~K}^{-2}$, and $\beta=0.0253,0.0375,0.0379$, $0.0345,0.0270 \mathrm{~mJ} \mathrm{moleatom}^{-1} \mathrm{~K}^{-4}$ for $x=0,5.9,11.1,15.8$ and 20 , respectively. Then the Debye temperature $\Theta_{\mathrm{D}}$ is calculated through the equation [40]:

$\Theta_{\mathrm{D}}=\left(12 \pi^{4} n R / 5 \beta\right)^{1 / 3}$,

where $n=1$ is the number of atoms per unit cell, and $R$ is the gas constant. This gives $\Theta_{\mathrm{D}}=425,373,372,383$, and $416 \mathrm{~K}$ for $x=0$, $5.9,11.1,15.8$ and 20 , respectively. These values, together with those of $\gamma$ and $\beta$, are listed in Table 1. It is noted that the $\gamma$ values for the HEAs are smaller or considerably smaller than those of $\mathrm{Nb}, \mathrm{Ta}, \mathrm{Mo}, \mathrm{W}$ and not much larger than that of $\mathrm{W}$, suggesting that they are not a "cocktail" of those of the constituent elements. In addition, the slight increase in $\gamma$ implies that the density of states at the Fermi level is not significantly affected by the $\mathrm{C}$ alloying. On the other hand, except for $x=0, \Theta_{\mathrm{D}}$ increases monotonically with $x$, which is as expected from the incor- poration of $\mathrm{C}$ with a light mass.

\section{Phase formation}

It is known that the phase formation of HEAs can be predicted $[18,41-43]$ using the parameters such as valence electron concentration (VEC), atomic size difference $(\delta)$ and mixing entropy $\left(\Delta S_{\text {mix }}\right)$, which are defined as $[18,42-43]$

$\mathrm{VEC}=\sum_{i=1} c_{i}(\mathrm{VEC})_{i}$,

$\delta=\sqrt{\sum_{i=1}^{n} c_{i}\left(1-r_{i} / \sum_{i=1}^{n} c_{i} r_{i}\right)^{2}}$,

$\Delta S_{\text {mix }}=-R \sum_{i=1}^{n} c_{i} \ln c_{i}$,

where $c_{i},(\mathrm{VEC})_{i}$ and $r_{i}$ are the molar fraction, number of valence electrons and atomic radius for the ith element, respectively. Empirically, a single bcc solid solution is expected to form when the following conditions are met: $\delta \leq 6.6 \%$ [18], $1.44 R \leq \Delta S_{\text {mix }} \leq$ $2.10 R$ [42], and VEC $<6.87$ [43]. For the $\mathrm{Nb}_{37.5} \mathrm{Ta}_{25} \mathrm{Mo}_{12.5} \mathrm{~W}_{12.5^{-}}$ $\operatorname{Re}_{12.5}$ HEA $(x=0)$, the VEC, $\delta$ and $\Delta S_{\text {mix }}$ are calculated to be 5.5 , $2.07 \%$ and $1.49 R$, respectively. Indeed, both the VEC and $\delta$ are well below the threshold value. However, $\Delta S_{\text {mix }}$ is only slightly above the lower bound and smaller than $(1.57 R)$ of the singlephase $\mathrm{Nb}_{20} \mathrm{Ta}_{30} \mathrm{Mo}_{15} \mathrm{~W}_{20} \mathrm{Re}_{15}$ HEA, which may explain why the $\mathrm{Nb}_{37.5} \mathrm{Ta}_{25} \mathrm{Mo}_{12.5} \mathrm{~W}_{12.5} \mathrm{Re}_{12.5} \mathrm{HEA}$ is multiphase. In this respect, it 
Table 1 Structural, mechanical and physical parameters of the $\left(\mathrm{Nb}_{0.375} \mathrm{Ta}_{0.25} \mathrm{Mo}_{0.125} \mathrm{~W}_{0.125} \mathrm{Re}_{0.125}\right)_{100-x} \mathrm{C}_{x} \mathrm{HEAs}$

\begin{tabular}{|c|c|c|c|c|c|}
\hline Parameter & $x=0$ & $x=5.9$ & $x=11.1$ & $x=15.8$ & $x=20$ \\
\hline$a(\AA)$ & 3.207 & 3.215 & 3.215 & 3.220 & 3.224 \\
\hline$H_{\mathrm{v}}(\mathrm{GPa})$ & 6.4 & 7.1 & 7.2 & 7.7 & 8.0 \\
\hline$\rho_{0}(\mu \Omega \mathrm{cm})$ & 36.8 & 39.8 & 45.0 & 49.9 & 54.1 \\
\hline$\rho_{300 \mathrm{~K}} / \rho_{0}$ & 1.33 & 1.33 & 1.32 & 1.28 & 1.24 \\
\hline$\gamma\left(\mathrm{mJ}\right.$ moleatom $\left.{ }^{-1} \mathrm{~K}^{-2}\right)$ & 1.59 & 1.87 & 1.94 & 1.94 & 1.97 \\
\hline$\beta\left(\mathrm{mJ}\right.$ moleatom $\left.{ }^{-1} \mathrm{~K}^{-4}\right)$ & 0.0253 & 0.0375 & 0.0379 & 0.0345 & 0.0270 \\
\hline$\Theta_{\mathrm{D}}(\mathrm{K})$ & 425 & 373 & 372 & 383 & 416 \\
\hline
\end{tabular}

is worth noting that the carbon atoms, no matter what sites they occupy, will contribute to the increase of $\Delta S_{\text {mix }}$. According to our calculations, $\Delta S_{\text {mix }}$ would rise to about $1.57 R$ as along as $\sim 3 \%$ of the lattice sites are occupied by the carbon atoms in the $\left(\mathrm{Nb}_{0.375} \mathrm{Ta}_{0.25} \mathrm{Mo}_{0.125} \mathrm{~W}_{0.125}-\mathrm{Re}_{0.125}\right)_{100-x} \mathrm{C}_{x}$ HEAs. Note that this corresponds to a VEC of 5.45 and a $\delta$ of $6.4 \%$, both of which still satisfy the criteria for forming a bcc solid solution. As for $\Delta S_{\text {mix }}$ from interstitial carbon atoms, its quantification is difficult due to the lack of a reliable structural model. In particular, the fractions of $\mathrm{C}$ interstitials in tetrahedral and octahedral sits remain to be determined by neutron diffraction techniques. Nonetheless, in analogy with other interstitial bcc systems such as $\mathrm{ZrH}_{x}$ [44], this additional $\Delta S_{\text {mix }}$ is expected to vary with $x$ and be in the order of $x R$. Taken together, it is reasonable to speculate that the enhanced mixing entropy induced by $\mathrm{C}$ alloying is mainly responsible for stabilizing the single bcc phase in the $\left(\mathrm{Nb}_{0.375} \mathrm{Ta}_{0.25} \mathrm{Mo}_{0.125} \mathrm{~W}_{0.125}-\mathrm{Re}_{0.125}\right)_{100-x} \mathrm{C}_{x}$ HEAs.

\section{CONCLUSIONS}

In summary, we have systematically studied the structural, mechanical, and physical properties of the $\left(\mathrm{Nb}_{0.375} \mathrm{Ta}_{0.25} \mathrm{Mo}_{0.125^{-}}\right.$ $\left.\mathrm{W}_{0.125} \operatorname{Re}_{0.125}\right)_{100-x} \mathrm{C}_{x}$ HEAs with $x$ up to 20 . The results show that:

(1) The bcc phase fraction increases from $76 \%$ for the C-free HEA $(x=0)$ to more than $99 \%$ for $x=20$.

(2) The increase of $\mathrm{C}$ content $x$ leads to an expansion of the bcc lattice, an enhancement of the microhardness, an increase in residual resistivity and a small variation of density of states at the Fermi level.

(3) For $x \geq 11.1$, there is evidence of bond formation between the carbon and metal atoms.

(4) The carbon atoms prefer to occupy the interstitial site, but may also reside in the lattice site at high $x$ values.

(5) $\Delta S_{\text {mix }}$, rather than VEC and $\delta$, plays a critical role in achieving the nearly single bcc phase.

These not only provide the first family of carbon interstitial HEAs with a bcc structure, but also help to better understand the phase formation in carbon alloyed refractory HEAs, which may assist in their design for practical applications.

Received 7 June 2021; accepted 8 July 2021;

published online 27 August 2021

1 Yeh JW, Chen SK, Lin SJ, et al. Nanostructured high-entropy alloys with multiple principal elements: Novel alloy design concepts and outcomes. Adv Eng Mater, 2004, 6: 299-303

2 Ye YF, Wang Q, Lu J, et al. High-entropy alloy: Challenges and prospects. Mater Today, 2016, 19: 349-362

3 Miracle DB, Senkov ON. A critical review of high entropy alloys and related concepts. Acta Mater, 2017, 122: 448-511
4 Zhang W, Liaw PK, Zhang Y. Science and technology in high-entropy alloys. Sci China Mater, 2018, 61: 2-22

5 George EP, Raabe D, Ritchie RO. High-entropy alloys. Nat Rev Mater, 2019, 4: 515-534

6 An Z, Mao S, Liu Y, et al. A novel HfNbTaTiV high-entropy alloy of superior mechanical properties designed on the principle of maximum lattice distortion. J Mater Sci Tech, 2021, 79: 109-117

7 Senkov ON, Senkova SV, Woodward C. Effect of aluminum on the microstructure and properties of two refractory high-entropy alloys. Acta Mater, 2014, 68: 214-228

8 Yu PF, Zhang LJ, Cheng $\mathrm{H}$, et al. The high-entropy alloys with high hardness and soft magnetic property prepared by mechanical alloying and high-pressure sintering. Intermetallics, 2016, 70: 82-87

9 Sanchez JM, Vicario I, Albizuri J, et al. Phase prediction, microstructure and high hardness of novel light-weight high entropy alloys. J Mater Res Tech, 2019, 8: 795-803

10 Cai YP, Wang GJ, Ma YJ, et al. High hardness dual-phase high entropy alloy thin films produced by interface alloying. Scripta Mater, 2019, 162: 281-285

11 Sha C, Zhou Z, Xie Z, et al. Extremely hard, $\alpha$-Mn type high entropy alloy coatings. Scripta Mater, 2020, 178: 477-482

12 Lee C, Chou Y, Kim G, et al. Lattice-distortion-enhanced yield strength in a refractory high-entropy alloy. Adv Mater, 2020, 32: 2004029

13 Hsu YJ, Chiang WC, Wu JK. Corrosion behavior of $\mathrm{FeCoNiCrCu}_{x}$ high-entropy alloys in $3.5 \%$ sodium chloride solution. Mater Chem Phys, 2005, 92: 112-117

14 Lee CP, Chen YY, Hsu CY, et al. The effect of boron on the corrosion resistance of the high entropy alloys $\mathrm{Al}_{0.5} \mathrm{CoCrCuFeNiB}_{x}$. J Electrochem Soc, 2007, 154: C424

15 Tang Z, Huang L, He W, et al. Alloying and processing effects on the aqueous corrosion behavior of high-entropy alloys. Entropy, 2014, 16: 895-911

16 Shi Y, Yang B, Xie X, et al. Corrosion of $\mathrm{Al}_{x} \mathrm{CoCrFeNi}$ high-entropy alloys: Al-content and potential scan-rate dependent pitting behavior. Corrosion Sci, 2017, 119: 33-45

17 Hua N, Wang W, Wang Q, et al. Mechanical, corrosion, and wear properties of biomedical Ti-Zr-Nb-Ta-Mo high entropy alloys. J Alloys Compd, 2021, 861: 157997

18 Zhang Y, Zuo TT, Tang Z, et al. Microstructures and properties of high-entropy alloys. Prog Mater Sci, 2014, 61: 1-93

19 Vaidya M, Guruvidyathri K, Murty BS. Phase formation and thermal stability of $\mathrm{CoCrFeNi}$ and $\mathrm{CoCrFeMnNi}$ equiatomic high entropy alloys. J Alloys Compd, 2019, 774: 856-864

20 Chang F, Cai B, Zhang C, et al. Thermal stability and oxidation resistance of $\mathrm{FeCr}_{x} \mathrm{CoNiB}$ high-entropy alloys coatings by laser cladding. Surf Coatings Tech, 2019, 359: 132-140

21 Whitfield TE, Pickering EJ, Owen LR, et al. An assessment of the thermal stability of refractory high entropy superalloys. J Alloys Compd, 2021, 857: 157583

22 Senkov ON, Wilks GB, Miracle DB, et al. Refractory high-entropy alloys. Intermetallics, 2010, 18: 1758-1765

23 Senkov ON, Wilks GB, Scott JM, et al. Mechanical properties of $\mathrm{Nb}_{25} \mathrm{Mo}_{25} \mathrm{Ta}_{25} \mathrm{~W}_{25}$ and $\mathrm{V}_{20} \mathrm{Nb}_{20} \mathrm{Mo}_{20} \mathrm{Ta}_{20} \mathrm{~W}_{20}$ refractory high entropy alloys. Intermetallics, 2011, 19: 698-706 
24 Zhang J, Hu Y, Wei Q, et al. Microstructure and mechanical properties of $\mathrm{Re}_{x} \mathrm{NbMoTaW}$ high-entropy alloys prepared by arc melting using metal powders. J Alloys Compd, 2020, 827: 154301

25 Bhandari U, Zhang C, Zeng C, et al. Computational and experimental investigation of refractory high entropy alloy $\mathrm{Mo}_{15} \mathrm{Nb}_{20} \mathrm{Re}_{15} \mathrm{Ta}_{30} \mathrm{~W}_{20}$. J Mater Res Tech, 2020, 9: 8929-8936

$26 \mathrm{Wu} \mathrm{Z}$, Parish CM, Bei H. Nano-twin mediated plasticity in carboncontaining FeNiCoCrMn high entropy alloys. J Alloys Compd, 2015, 647: 815-822

27 Wang Z, Baker I, Cai Z, et al. The effect of interstitial carbon on the mechanical properties and dislocation substructure evolution in $\mathrm{Fe}_{40.4^{-}}$ $\mathrm{Ni}_{11.3} \mathrm{Mn}_{34.8} \mathrm{Al}_{7.5} \mathrm{Cr}_{6}$ high entropy alloys. Acta Mater, 2016, 120: 228-239

28 Li Z, Tasan CC, Springer H, et al. Interstitial atoms enable joint twinning and transformation induced plasticity in strong and ductile high-entropy alloys. Sci Rep, 2017, 7: 40704

29 Wang Z, Baker I. Interstitial strengthening of a f.c.c. FeNiMnAlCr high entropy alloy. Mater Lett, 2016, 180: 153-156

30 Chen LB, Wei R, Tang K, et al. Heavy carbon alloyed FCC-structured high entropy alloy with excellent combination of strength and ductility. Mater Sci Eng-A, 2018, 716: 150-156

31 Zhang C, Bhandari U, Zeng C, et al. Carbide formation in refractory $\mathrm{Mo}_{15} \mathrm{Nb}_{20} \mathrm{Re}_{15} \mathrm{Ta}_{30} \mathrm{~W}_{20}$ alloy under a combined high-pressure and hightemperature condition. Entropy, 2020, 22: 718

32 Casillas-Trujillo L, Jansson U, Sahlberg M, et al. Interstitial carbon in bcc HfNbTiVZr high-entropy alloy from first principles. Phys Rev Mater, 2020, 4: 123601

33 ISO 6507-1: 2018. Metallic materials-Vickers hardness test-Part I: Test method. 2018

34 Tarutani Y, Kudo M. Atomic radii and lattice parameters of the A15 crystal structure. J Less Common Met, 1977, 55: 221-229

35 Otto F, Dlouhý A, Somsen C, et al. The influences of temperature and microstructure on the tensile properties of a CoCrFeMnNi highentropy alloy. Acta Mater, 2013, 61: 5743-5755

36 Zhu Q, Xiao G, Cui Y, et al. Anisotropic lattice expansion and enhancement of superconductivity induced by interstitial carbon doping in rhenium. J Alloys Compd, 2021, 878: 160290

37 Cui Y, Wu J, Liu B, et al. Superconductivity and high hardness in metal-rich carbides $\mathrm{MoRe}_{2} \mathrm{C}$ and $\mathrm{WRe}_{2} \mathrm{C}$. J Alloys Compd, 2021, 856: 157314

38 Teghil R, D'Alessio L, Zaccagnino M, et al. TiC and TaC deposition by pulsed laser ablation: A comparative approach. Appl Surf Sci, 2001, 173: 233-241

39 Wang X, Meng S, Zhang X, et al. Multi-type carbon doping of $\mathrm{TiO}_{2}$ photocatalyst. Chem Phys Lett, 2007, 444: 292-296

40 Kittel C. Introduction to Solid State Physics. New York: John Wiley \& Sons Inc., 1996

41 Zhang Y, Zhou Y, Lin J, et al. Solid-solution phase formation rules for multi-component alloys. Adv Eng Mater, 2008, 10: 534-538

42 Takeuchi A, Inoue A. Classification of bulk metallic glasses by atomic size difference, heat of mixing and period of constituent elements and its application to characterization of the main alloying element. Mater Trans, 2005, 46: 2817-2829

43 Guo S, Ng C, Lu J, et al. Effect of valence electron concentration on stability of fcc or bcc phase in high entropy alloys. J Appl Phys, 2011, 109: 103505

44 Garcés J. A probabilistic description of the configurational entropy of mixing. Entropy, 2014, 16: 2850-2868

Acknowledgements We thank the foundation of Westlake University for financial support. The work at Zhejiang University was supported by the National Key Research and Development Program of China (2017YFA0303002)

Author contributions Cui $\mathrm{Y}$ initialized the project, synthesized the samples and did the physical property measurements with the assistance from Zhu Q, Xiao G, Yang W, Liu Y and Cao GH. Ren Z supervised the project and wrote the paper with input from Cui Y.
Conflict of interest

The authors declare that they have no conflict of interest.

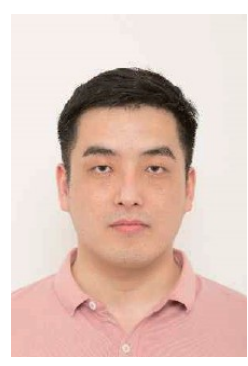

Yanwei Cui is currently a PhD student at the School of Science, Westlake University. He received his double bachelor degree from Chuzhou University in 2014, and master degree from Anhui Normal University in 2018. His research interests include the exploration and characterization of novel superconductors and functional materials.

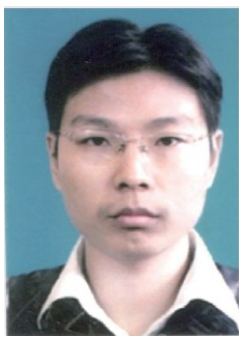

Zhi Ren has been a principle investigator at the School of Science, Westlake University since 2017. He received his bachelor and doctoral degrees from Zhejiang University in 2004 and 2009, respectively. $\mathrm{He}$ was a specially appointed researcher at Osaka University from 2009 to 2012 and a postdoctoral assistant at the University of Geneva from 2013 to 2017. His research interests include the superconductivity and topological quantum state of materials.

\section{具有体心立方结构的碳间隙难熔高熵合金}

崔艳威 $1,2,3$, 祝钦清 $1,2,4$, 肖国锐 ${ }^{1,2,3}$, 杨武璋 $1,2,4$, 刘 亚涁 ${ }^{3}$, 曹光旱 ${ }^{3}$, 任之 ${ }^{1,2^{*}}$

摘要 间隙碳掺杂是改善高熵合金性能的一种有效方法. 然而, 迄今为 止的相关探索局限于具有面心立方结构的高熵合金体系. 本文系统研 究了难熔高熵合金 $\left(\mathrm{Nb}_{0.375} \mathrm{Ta}_{0.25} \mathrm{Mo}_{0.125} \mathrm{~W}_{0.125} \mathrm{Re}_{0.125}\right)_{100-x} \mathrm{C}_{x}(x=0,5.9$, $11.1,15.8,20)$ 的结构、力学和物理性能. 实验结果显示, 虽然初始的 $\mathrm{Nb}_{37.5} \mathrm{Ta}_{25} \mathrm{Mo}_{12.5} \mathrm{~W}_{12.5} \mathrm{Re}_{12.5}$ 高熵合金 $(x=0)$ 具有体心立方结构的主相和 明显的杂相, 其体心立方相的比例随着碳含量的增加而增加, 并在 $x$ 为 20 时接近 $100 \%$. 不仅如此, 碳含量的增加导致体心立方晶格的膨胀、韦 氏硬度的增强、剩余电阻率的增大，以及费米面附近的态密度的微小 变化. 所有这些特征与碳原子占据间隙位的预期一致. 当碳含量大于或 等于11.1时, X射线光电子能谱研究结果表明碳和金属原子间形成化学 键，暗示一部分碳原子也可能占据晶格位. 此外，半定量分析表明碳原 子的引入导致的混合熵增加对稳定(近乎)单相固溶体发挥了关键作用. 我们的工作不仅揭示了第一个具有体心立方结构的碳间隙高熵合金系 列, 而且有助于更好地理解碳在难熔高熵合金中的合金化行为. 